\title{
Prompt Management Is Most Important for Colonic Perforation After Colonoscopy
}

\author{
Hyun-Ho Kim, Bong-Hyeon Kye, Hyung-Jin Kim, Hyeon-Min Cho \\ Department of Surgery, St. Vincent's Hospital, The Catholic University of Korea College of Medicine, Suwon, Korea
}

\begin{abstract}
Purpose: The incidence of complications after colonoscopy is very low. The complications after colonoscopy that are of clinical concern are bleeding and perforation. The present study was conducted to determine the clinical outcomes and the risk factors of a colostomy or a colectomy after colonoscopic colon perforation.

Methods: From March 2009 to December 2012, the records of all patients who were treated for colorectal perforation after colonoscopy were reviewed retrospectively. The following parameters were evaluated: age, sex, purpose of colonoscopy, management of the colonic perforation, and interval from colonoscopy to the diagnosis of a colonic perforation. A retrospective analysis was performed to determine the risk factors associated with major surgery for the treatment of a colon perforation after colonoscopy.

Results: A total 27 patients were included in the present study. The mean age was 62 years, and 16 were males. The purpose of colonoscopy was diagnostic in 18 patients. The most common perforation site was the sigmoid colon. Colonic perforation was diagnosed during colonoscopy in 14 patients, just after colonoscopy in 5 patients, and 24 hours or more after colonoscopy in 8 patients. For the treatment of colonic perforation, endoscopic clipping was performed in 3 patients, primary closure in 15 patients, colon resection in 2 patients, Hartmann's procedures in 4 patients, and diverting colostomy in 3 patients. If the diagnosis of perforation after colonoscopy was delayed for more than 24 hours, the need for major treatment was increased significantly.

Conclusion: Although a colonic perforation after colonoscopy is rare, if the morbidity and the mortality associated with the colonic perforation are to be reduced, prompt diagnosis and management are very important.
\end{abstract}

Keywords: Intestinal perforation; Colonoscopy

\section{INTRODUCTION}

The incidence of complications after colonoscopy is very low. However, recently, as the numbers of diagnostic screening colonoscopy and therapeutic colonoscopy are increasing, the cases of complications associated with colonoscopy are also increasing.

Received: February 25, 2014 - Accepted: September 24, 2014

Correspondence to: Hyung-Jin Kim, M.D.

Department of Surgery, St. Vincent's Hospital, The Catholic University of

Korea College of Medicine, 93 Jungbu-daero, Paldal-gu, Suwon 442-723,

Korea

Tel: +82-31-249-8303, Fax: +82-31-247-5347

E-mail: hj@catholic.ac.kr

(C) 2014 The Korean Society of Coloproctology

This is an open-access article distributed under the terms of the Creative Commons Attribution NonCommercial License (http://creativecommons.org/licenses/by-nc/3.0) which permits unrestricted noncommercial use, distribution, and reproduction in any medium, provided the original work is properly cited.
Most of the complications after colonoscopy are self-liming complications, such as abdominal pain, abdominal or anal discomfort, diarrhea, and nausea [1]. The complications after colonoscopy that are of clinical concern are bleeding and colon perforation. Especially colon perforation usually needs emergency surgery and may be associated with significant morbidity and mortality. The incidence of colon perforation is known to be $0.1 \%$ after diagnostic colonoscopy and $0.2 \%$ after therapeutic colonoscopy [1$3]$. The present study was conducted to determine the clinical outcomes and the risk factors of a colectomy or a fecal diversion for the treatment of colon perforation after colonoscopy.

\section{METHODS}

This study was approved by the Institutional Review Board of St. Vincent's Hospital, The Catholic University of Korea (VC13RISI 0200). From March 2009 to December 2012, the cases of all pa- 
tients who were treated for colorectal perforation after colonoscopy at our hospital were reviewed retrospectively. The colonoscopy may have been performed in our hospital or another hospital. The following parameters were evaluated: age, sex, comorbidity, purpose of colonoscopy (diagnostic or therapeutic), management of colonic perforation, interval from colonoscopy to the diagnosis of the colon perforation, hospital stay, and morbidity and mortality.

A retrospective analysis was performed to determine the risk factors of major surgery for the treatment of colon perforation after colonoscopy. We defined the patients who were treated by using endoscopic clipping or primary closure as the minor treatment group and the patients who were treated by using a colectomy or a fecal diversion as the major treatment group. Categorical variables were compared using chi-square tests, and numerical variables were compared using independent t-tests or MannWhitney tests. A P-value less than 0.05 was regarded as statistically significant. All analyses were performed using SPSS ver. 17 (SPSS Inc., Chicago, IL, USA).

\section{RESULTS}

A total 27 patients were included in the present study. The mean age was $62 \pm 10$ years, and there were 16 male and 11 female patients. As for comorbidity, 14 patients had medical diseases or history of medical diseases: 1 patient with Crohn's disease, 9 patients with hypertension, 4 patients with diabetes mellitus, and 4 patients with a history of cerebrovascular disease.

The diagnosis of the colon perforation was made by using a plain X-ray and computed tomography (CT). The colonoscopy was performed on 7 patients at our hospital and on 20 patients at other hospitals. During the study period, 24,521 colonoscopies were performed in our hospital, and the rate of colon perforation after colonoscopy at our hospital was about $0.03 \%$. In this study, the purpose of colonoscopy was diagnostic in 18 patients and therapeutic in 9 patients. The most common perforation site was the sigmoid colon (between the rectosigmoid colon and the sigmoid-descending colon junction) (Fig. 1). As for diagnostic colonoscopy, $77.8 \%$ of the perforations (14/18) developed in the sigmoid colon whereas for therapeutic colonoscopy, most of the perforations developed at the polypectomy site. Colonic perforation was diagnosed during colonoscopy in 14 patients, just after colonoscopy in 5 patients, and more than 24 hours after colonoscopy in 8 patients. Among 27 patients, there were three patients who had history of abdominal surgery (appendectomy, laparoscopic cholecystectomy, and cholecystectomy, respectively).

For the treatment of a colonic perforation, endoscopic clipping was performed in 3 patients, primary closure in 15 patients, colon resection in 2 patients, Hartmann's procedures in 4 patients, and a diverting colostomy in 3 patients. Of the primary repairs, $86.7 \%$ $(13 / 15)$ were performed by using laparoscopic surgery. Between the minor treatment and the major treatment groups, no signifi-

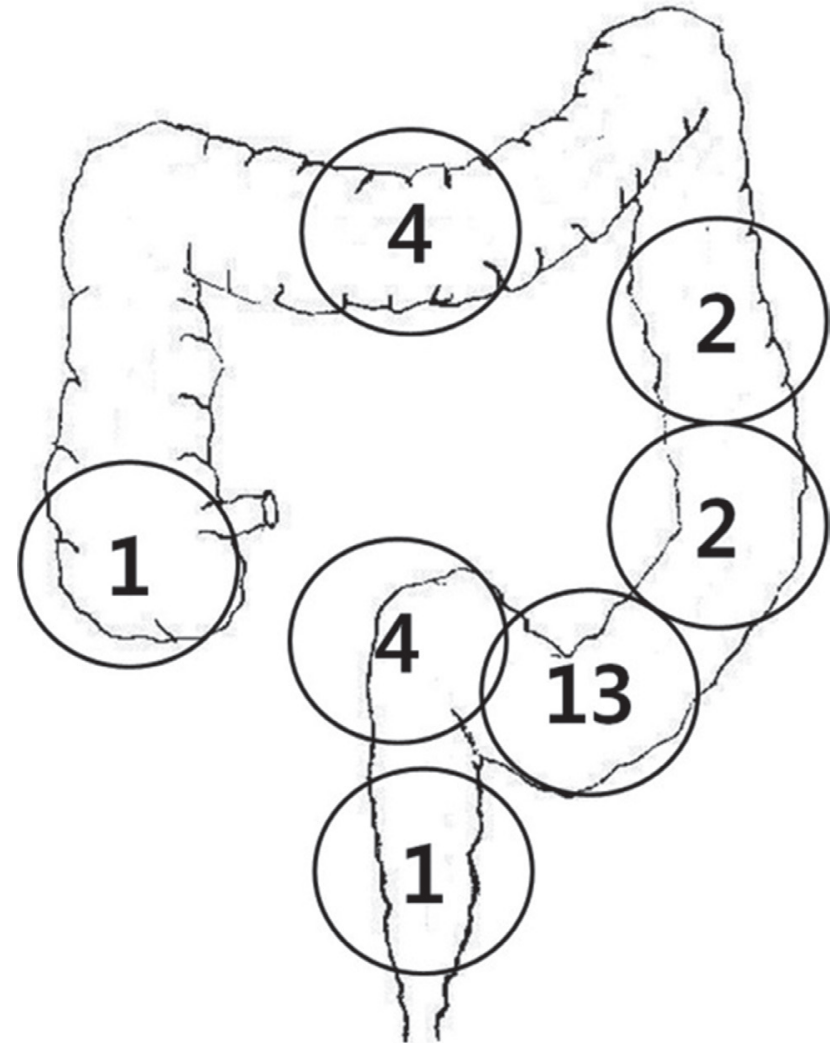

Fig. 1. Number of cases according to the site of colon perforation.

cant differences in sex, age, location of the perforation, or the purpose of colonoscopy were observed. However, if the diagnosis of perforation after colonoscopy had been delayed by more than 24 hours, the need for major treatment was increased significantly (Table 1). No mortality was associated with colon perforation.

\section{DISCUSSION}

Many kinds of complications may develop after colonoscopy. However, most of the complications, such as abdominal discomfort, pain, diarrhea, and nausea, are not so serious and can be resolved without any treatments [1]. The complications after colonoscopy that are of clinical concern are bleeding and colon perforation. These complications are relatively rare, but if they occur, the consequences can be serious.

Colon perforation is the most serious complication after colonoscopy. Its incidence is known to be $0.1 \%$ after diagnostic colonoscopy, $0.2 \%$ after therapeutic colonoscopy such as polypectomy, and up to $10 \%$ after colonoscopic submucosal dissection [1-3]. If colon perforation develops, panperitonitis, acute abdominal compartment syndrome, ostomy creation, or death may develop [4]. The most common site of colon perforation is the sigmoid colon [5]. In the present study, we also found that $70.4 \%$ of the colon perforations developed at the sigmoid colon. The causes of colon 
Table 1. Risk factors of major treatment for colon perforation after colonoscopy

\begin{tabular}{|c|c|c|c|}
\hline Variable & $\begin{array}{l}\text { Minor treatment } \\
\quad(n=18)\end{array}$ & $\begin{array}{l}\text { Major treatment } \\
\qquad(\mathrm{n}=9)\end{array}$ & P-value \\
\hline Age $(y r)$, mean $\pm S D$ & $61.0 \pm 10.1$ & $64.1 \pm 9.8$ & 0.455 \\
\hline Sex & & & 0.166 \\
\hline Male & 9 & 7 & \\
\hline Female & 9 & 2 & \\
\hline \multicolumn{4}{|l|}{ Comorbidity } \\
\hline Crohn's disease & 1 & 0 & 0.471 \\
\hline Hypertension & 5 & 4 & 0.386 \\
\hline Diabetes mellitus & 3 & 1 & 0.702 \\
\hline $\begin{array}{l}\text { History of cerebrovascular } \\
\text { disease }\end{array}$ & 2 & 2 & 0.444 \\
\hline Purpose of colonoscopy & & & 0.083 \\
\hline Diagnostic & 14 & 4 & \\
\hline Therapeutic & 4 & 5 & \\
\hline Location & & & 0.136 \\
\hline Sigmoid colon & 11 & 8 & \\
\hline Other & 7 & 1 & \\
\hline $\begin{array}{l}\text { Intervals of diagnosis of colon } \\
\text { perforation }\end{array}$ & & & 0.003 \\
\hline Within 24 hours & 16 & 3 & \\
\hline After 24 hours & 2 & 6 & \\
\hline $\begin{array}{l}\text { Length of hospital stay, } \\
\text { mean } \pm \text { SD }\end{array}$ & $10.0 \pm 6.5$ & $14.0 \pm 6.5$ & 0.017 \\
\hline
\end{tabular}

perforation are forceful passage of the colonoscope through a loop, bowing of the sigmoid colon, narrowing from diverticular disease, adhesion from previous pelvic operation, and others. The risk factors for colon perforations are older age, female gender, a polypectomy, hot biopsy, pre-existing colonic disease such as inflammatory bowel disease, and large polyps [6-8]. Therefore, proper selection of the patient, minimal air insufflation during colonoscope insertion, avoidance of severe abdominal pain, and avoidance of forceful colonoscope insertion are needed to reduce the colon perforation rate.

If the patient complains of continuous abdominal pain and distension after colonoscopy, a chest PA and abdominal x-ray should be taken as soon as possible, and the presence of pneumoperitoneum should be evaluated immediately. When the colon perforation is noted during colonoscopy, endoscopic repair using a clip or band ligation can be effective for its treatment [9-11]. Also, if the symptoms of peritonitis are minimal, conservative care with bowel rest and antibiotic therapy can be administered. However, emergency surgery is needed for most colonic perforations. Primary repair of the colonic perforation can be done when the peri-

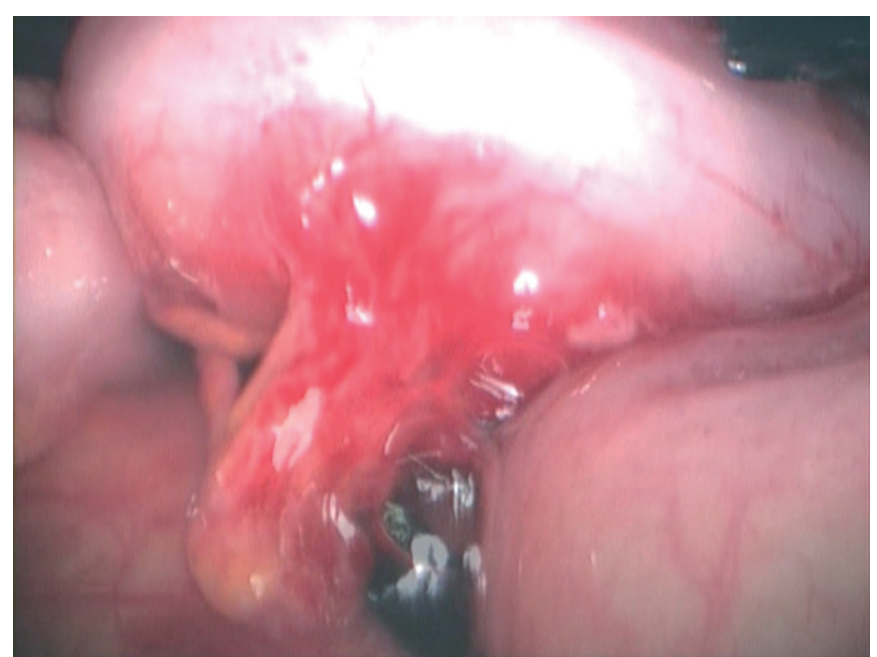

Fig. 2. Air leak test with transanal air insufflation for finding the site of colon perforation.

toneal contamination is minimal. However, if the peritoneal contamination is severe or the perforation site is large, a colon resection, such as Hartmann's procedures or fecal diversion, is needed. In some cases, the site of the colon perforation cannot be found; in those cases, air insufflation through the anus may help in detecting the colon perforation's site (Fig. 2).

Patients who undergo minor treatments, such as colonoscopic clipping or primary closure, usually recover without any complications. However, patients who undergo major treatments, such as a colectomy or Hartmann's procedures, usually need fecal diversion. In the present study, primary repair, without any postoperative complications, was performed in 15 patients, and in 13 of those 15 patients, it was performed laparoscopically. However, in 8 of the 9 patients who needed a colectomy or a fecal diversion, a laparotomy was performed. The significant differences between these two groups were the time interval between the colonoscopy and the diagnosis of colon perforation and the length of hospital stay (Table 1). Thus, even though colon perforations after colonoscopy cannot be completely eliminated, secondary events associated colon perforation can be reduce, and early diagnosis of colonic perforation after colonoscopy is the most important thing for reducing number of secondary events.

In conclusion, although a colon perforation after colonoscopy is not common, if the diagnosis of colon perforation is delayed for more than 24 hours, most patients will require a colectomy or fecal diversion. Therefore, if the morbidity and the mortality associated with colon perforation are to be reduced, prompt diagnosis and management are very important.

\section{CONFLICT OF INTEREST}

No potential conflict of interest relevant to this article was reported. 


\section{REFERENCES}

1. Ko CW, Dominitz JA. Complications of colonoscopy: magnitude and management. Gastrointest Endosc Clin N Am 2010;20:65971.

2. Samalavicius NE, Kazanavicius D, Lunevicius R, Poskus T, Valantinas J, Stanaitis J, et al. Incidence, risk, management, and outcomes of iatrogenic full-thickness large bowel injury associated with 56,882 colonoscopies in 14 Lithuanian hospitals. Surg Endosc 2013;27:1628-35.

3. Hagel AF, Boxberger F, Dauth W, Kessler HP, Neurath MF, Raithel M. Colonoscopy-associated perforation: a 7-year survey of inhospital frequency, treatment and outcome in a German university hospital. Colorectal Dis 2012;14:1121-5.

4. Souadka A, Mohsine R, Ifrine L, Belkouchi A, El Malki HO. Acute abdominal compartment syndrome complicating a colonoscopic perforation: a case report. J Med Case Rep 2012;6:51.

5. Matharoo GS, Goldfarb MA. Treatment and outcomes of iatrogenic colon perforations at a community teaching hospital. Am Surg 2012;78:975-8.

6. Rutter CM, Johnson E, Miglioretti DL, Mandelson MT, Inadomi J,
Buist DS. Adverse events after screening and follow-up colonoscopy. Cancer Causes Control 2012;23:289-96.

7. Hagel AF, Boxberger F, Dauth W, Kessler HP, Neurath MF, Raithel M. Colonoscopy-associated perforation: a 7-year survey of inhospital frequency, treatment and outcome in a German university hospital. Colorectal Dis 2012;14:1121-5.

8. Lee EJ, Lee JB, Choi YS, Lee SH, Lee DH, Kim do S, et al. Clinical risk factors for perforation during endoscopic submucosal dissection (ESD) for large-sized, nonpedunculated colorectal tumors. Surg Endosc 2012;26:1587-94.

9. Kim JS, Kim BW, Kim JI, Kim JH, Kim SW, Ji JS, et al. Endoscopic clip closure versus surgery for the treatment of iatrogenic colon perforations developed during diagnostic colonoscopy: a review of 115,285 patients. Surg Endosc 2013;27:501-4.

10. Han JH, Park S, Youn S. Endoscopic closure of colon perforation with band ligation; salvage technique after endoclip failure. Clin Gastroenterol Hepatol 2011;9:e54-5.

11. Cho SB, Lee WS, Joo YE, Kim HR, Park SW, Park CH, et al. Therapeutic options for iatrogenic colon perforation: feasibility of endoscopic clip closure and predictors of the need for early surgery. Surg Endosc 2012;26:473-9. 